\title{
Impacts of Unsaturated Conditions on The Ultimate Axial Capacity of Energy Piles
}

\author{
Fatemah Behbehani ${ }^{1, *}$ and John S. McCartney ${ }^{2}$ \\ ${ }^{1}$ Ph.D Student, Department of Structural Engineering, UC San Diego, 9500 Gilman Dr., La Jolla, CA 92093-0085, USA \\ ${ }^{2}$ Professor and Chair, Department of Structural Engineering, UC San Diego, 9500 Gilman Dr., La Jolla, CA 92093-0085, USA
}

\begin{abstract}
This study uses concepts from unsaturated soil mechanics to explain changes in axial capacity observed in geotechnical centrifuge experiments on semi-floating energy piles in unsaturated silt heated monotonically to different temperatures. Thermally-induced drying of the unsaturated silt surrounding energy piles was observed during heating using temperature-corrected dielectric sensor readings. An effective stress-based equation for estimating the ultimate capacity was calibrated using the load-settlement curves for a pile at room-temperature, which was then used to estimate the ultimate capacities of energy piles under elevated temperatures using measured changes in degree of saturation near the energy pile. The predicted capacity matched well with the capacity from the experimental load-settlement curves, confirming the relevance of the effective stress principle in unsaturated soils in nonisothermal conditions and the importance of considering coupled heat transfer and water flow in unsaturated soils surrounding energy piles.
\end{abstract}

\section{Introduction}

Goode and McCartney [1] evaluated the thermomechanical response of semi-floating energy piles in unsaturated, compacted silt and dry sand. They found that the axial capacity of the energy piles in unsaturated silt increased with pile temperature, while the axial capacity of the energy piles in dry sand did not. However, they did not evaluate the mechanism behind the increase in capacity of the energy piles in silt with temperature. This paper presents additional information from dielectric sensors that were monitored in these tests but were not originally reported due to the lack of a methodology for correcting the effects of temperature on the sensors. Since that time, Iezzoni and McCartney [2] developed a temperature correction for the dielectric sensors and defined parameters in the correction specific to silt. This paper uses the corrected dielectric sensors results in an effective stress analysis accounting for the effects of coupled heat transfer and water flow in unsaturated soils to estimate the axial capacity of the energy piles.

The model-scale semi-floating energy pile tested by Goode and McCartney [1] has a diameter of $63.5 \mathrm{~mm}$ and a length of $342.9 \mathrm{~mm}$. When scaled by a centripetal acceleration of $24 \mathrm{~g}$, this corresponds to a prototype energy pile with a diameter of $1.5 \mathrm{~m}$ and a length of $8.2 \mathrm{~m}$. The prototype dimensions were used to analyze the model results. Bonny silt was compacted below and around the energy pile in the centrifuge container shown in Figure 1 to a depth of $533.4 \mathrm{~mm}$. The silt layer had a uniform initial water content and dry unit weight, which are summarized in Table 1 along with relevant properties.

Table 1. Bonny Silt Properties and Initial Conditions in the Study of Goode and McCartney [1].

\begin{tabular}{|c|c|}
\hline Parameter & Value \\
\hline $\mathrm{G}_{\mathrm{s}}$ & 2.6 \\
\hline Effective friction angle, $\phi^{\prime}$ & $32.4^{\circ}$ \\
\hline Standard Proctor maximum dry unit weight & $16.9 \mathrm{kN} / \mathrm{m}^{3}$ \\
\hline $\begin{array}{c}\text { Standard Proctor maximum optimum } \\
\text { gravimetric water content }\end{array}$ & $13.6 \%$ \\
\hline Initial void ratio, $\mathrm{e}_{0}$ & 0.63 \\
\hline Initial gravimetric water content, $\mathrm{w}_{0}$ & $14.2 \%$ \\
\hline Initial degree of saturation, $\mathrm{S}_{0}$ & 0.59 \\
\hline
\end{tabular}

After reaching a target centripetal acceleration of $24 \mathrm{~g}$ and stabilization of the displacement measurements, a seating axial load of $400 \mathrm{kN}$ (prototype scale) was applied to the pile. One energy pile was tested at room temperature $\left(21.4{ }^{\circ} \mathrm{C}\right)$, while two others were heated to have average changes in pile temperature along their length of $10{ }^{\circ} \mathrm{C}$ and $18{ }^{\circ} \mathrm{C}$. After maintaining the target temperature for 30 minutes, the energy piles were axially loaded to the maximum capacity of the loading piston (approximately $2000 \mathrm{kN}$ for the tests on the energy piles in unsaturated silt) and then unloaded. The temperature and the volumetric water content of the soil surrounding the energy pile were measured using dielectric sensors (Model EC-TM from Decagon Devices of Pullman, WA). The temperature was also monitored using thermocouple profile probes installed at different radial

Corresponding author: fnbeh@eng.ucsd.edu 
and horizontal distances from the pile. During the tests, the pile head displacement and soil surface displacements at different locations from the pile were measured using linearly variable differential transformers (LVDTs). The data from all these sensors except the dielectric sensors are presented in Goode and McCartney [1]. The locations of the sensors in the container are shown in Figure 1.

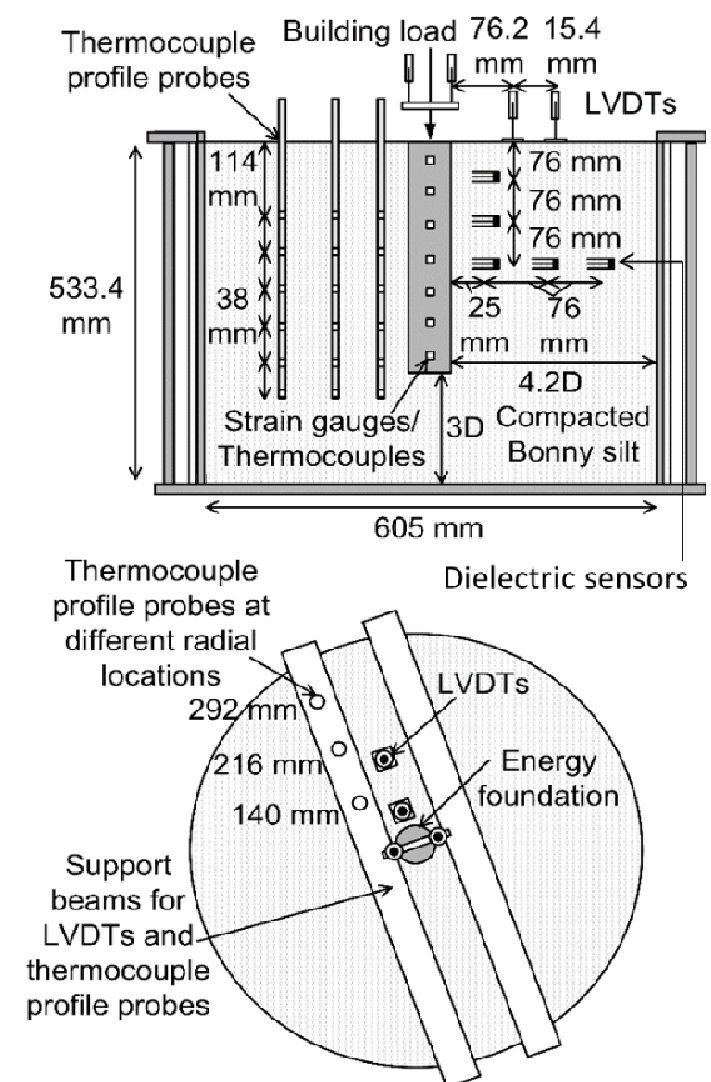

Fig. 1. Setup and model-scale locations of instrumentation in energy pile experiments of Goode and McCartney [1]

\section{Background}

\subsection{Effective stress in unsaturated soils}

In soil mechanics, the effective stress $\sigma^{\prime}$ controls the physical behavior of the soil, including the undrained shear strength $c_{u}$. For unsaturated soil, the effective stress depends on the pore air pressure $u_{a}$, pore water pressure $u_{w}$, and the voids content. Bishop and Blight [3] defined the effective stress of unsaturated soil as follows:

$$
\sigma^{\prime}=\left(\sigma-u_{a}\right)+\chi\left(u_{a}-u_{w}\right)
$$

where $\sigma$ is the total stress, $u_{a}$ is the pore air pressure, $u_{w}$ is the pore water pressure and $\chi$ is the effective stress parameter. The term $\left(u_{a}-u_{w}\right)$ is the matric suction which can also be written as $\psi$. The effective stress parameter $\chi$ varies between zero and one and defined in this study following the approach of Lu et al. (2010), as follows:

$$
\chi=S_{e}=\frac{S-S_{r}}{1-S_{r}}
$$

where $S_{e}$ is the effective degree of saturation, $S$ is the degree of saturation, and $S_{r}$ is the residual degree of saturation. The matric suction $\psi$ in unsaturated soil under elevated temperatures can be related to the effective saturation via the soil-water retention curve (SWRC) of Grant and Salehzadeh [4], as follows:

$$
\psi=\left(\frac{1}{S_{e}^{\frac{n_{G S}}{n_{G S}-1}}}-1\right)^{\frac{1}{n_{G S}}} /\left(\alpha_{G S} \frac{\beta_{0}+T_{r}}{\beta_{0}+T}\right)
$$

where $n_{G S}$ and $\alpha_{G S}$ are fitting parameters that depend on the soil characteristics and pore size distribution, $\beta_{0}$ is a soil-specific thermal parameter, $T$ is the actual temperature, and $T_{r}$ is the reference temperature. Alsherif and McCartney [5] found that the value of $\beta_{0}$ is equal to $-400 \mathrm{~K}$ for Bonny silt, and the values of $n_{G S}$ and $\alpha_{G S}$ are equal to 1.61 and $0.33 \mathrm{kPa}^{-1}$, respectively. The undrained shear strength $c_{u}$ of unsaturated soil at a given $\sigma^{\prime}$ calculated from Equation (1) can be estimated as follows:

$$
c_{u}=\sigma^{\prime} \tan \left(\phi^{\prime}\right)
$$

where $\sigma^{\prime}$ is the effective stress prior to undrained shearing and $\phi^{\prime}$ is the drained friction angle.

\subsection{Prediction of pile ultimate axial capacity}

The predicted ultimate axial capacity $Q_{u l t}$ of a pile is equal to the sum of the predicted end bearing capacity $Q_{b}$ and the predicted side shear capacity, $Q_{s}$ as follows:

$$
Q_{u l t}=Q_{b}+Q_{s}
$$

The end bearing capacity $Q_{b}$ is calculated as follows:

$$
Q_{\mathrm{b}}=A_{b} q_{b}
$$

where $A_{b}$ is the area of the pile base and $q_{b}$ is the base resistance, defined as follows for undrained pile loading:

$$
q_{b}=\left(N_{c} d_{c} S_{c}\right) c_{u}
$$

where $N_{c}$ is the bearing capacity factor, $d_{c}$ is the depth factor, $S_{c}$ is a shape factor, and $c_{u}$ is the undrained shear strength of the soil. For deep foundations, the product $N_{c} d_{c} s_{c}$ is equal to approximately 9 . In this study, the undrained bearing capacity was used because the load was applied relatively quickly in the centrifuge. The side shear capacity of a pile $Q_{s}$ is calculated as follows:

$$
Q_{\mathrm{s}}=A_{s} q_{\mathrm{s}}
$$

where $A_{s}$ is the area of the pile shaft and $q_{s}$ is the side shear resistance. The side shear resistance may be affected by the pile type, pile geometry, soil type, soil stress history, and the pile installation method. The energy piles tested by Goode and McCartney [1] were in compacted soils, which does not necessarily represent the conditions that may be encountered for energy piles in the field. Accordingly, there is no established method to predict the side shear resistance of piles in compacted 
soils. The side shear resistance was calculated using the beta method or alpha methods calibrated from the roomtemperature tests. For example, the side shear resistance can be estimated using the beta method as follows:

$$
q_{s}=\beta \sigma^{\prime}
$$

where $\beta$ is the Bjerrum-Burland coefficient [6-8] that can be calibrated based on observed load-settlement curves and is assumed to be temperature-independent. However, the following equation helps understand the variables affecting $\beta$ :

$$
\beta=K(\mathrm{OCR})^{0.5} \tan (\delta)
$$

where $K$ represents the coefficient of lateral earth pressure after compaction which is likely greater than the value of lateral earth pressure at rest $\left(K_{0}=1-\sin \phi^{\prime}\right)$, the soil-pile interface friction angle $\delta$ can be estimated to be about $95 \% \phi^{\prime}$ in the case of concrete-soil interfaces, and the OCR of a compacted soil is likely to be greater than 1.0 .

Alternatively, the alpha method can be used to estimate the side shear resistance with the undrained shear strength calculated from Equation (4), as follows:

$$
q_{s}=\alpha c_{u}
$$

where $\alpha$ is an empirical constant that can be calibrated based on observed load-settlement curves and is assumed to be temperature-independent.

Several studies have found that the radial thermal expansion of energy piles does not significantly affect the horizontal stress and thus the side shear resistance [9-12], so the effects of radial stresses in this study are ignored.

\subsection{Thermally Induced Water Flow in Unsaturated Soils}

Water flow in unsaturated soils under thermal gradients has been evaluated in several studies [13-16]. There are several mechanisms for thermally induced water flow in unsaturated soils. The first is related to temperature effects on water properties. The density and viscosity of water, the air-water surface tension, and the saturated vapor concentration are all dependent on temperature and thermally-induced spatial variations in these properties will lead to water flow [4]. The second mechanism is related to changes in soil properties with temperature, including the shape of the soil-water retention curve (SWRC) and the hydraulic conductivity. The third mechanism is related to phase change of pore water from liquid to vapor near a heat source, followed by vapor diffusion away from the heat source and condensation at a lower temperature locations where latent energy is released. Although these different mechanisms lead to drying of soils near heat sources, they will also result in a suction gradient in the soil that will tend to draw liquid water back toward the heat source. This may lead to the formation of a convection cell during heating of unsaturated soils.

Limited studies have investigated the behavior of energy piles in unsaturated soils, focusing on the impacts of thermally induced water flow on the heat transfer and thermo-mechanical response of the pile. Akrouch et al. [17] conducted an experiment to study the degree of saturation effects on the thermodynamic efficiency of energy piles. They found that the degree of saturation of unsaturated soils will impact the rate of the heat exchange of energy piles and found that the heat transfer efficiency of dry soil was $40 \%$ lower than that for saturated soil. The information in this study will help to better understand how thermally induced water flow in unsaturated soils can be combined with effective stress analyses to interpret the behavior of energy piles in unsaturated soils.

\section{Results and Analysis}

\subsection{Interpretation of Load-Settlement Curves}

The first step in the analysis of the behavior of the energy piles in unsaturated silt reported by Goode and McCartney [1] is to estimate the ultimate capacity of the energy piles from the experimental results. For simplicity, the criterion of Davisson [18] was used, which estimates the ultimate capacity $Q_{\text {ult }}$ to be the value on the load-settlement curve corresponding to a settlement $s_{\text {ult }}$ value estimated as follows:

$$
s_{u l t}=0.004 L_{r}+\frac{D}{120}+\frac{Q_{u l t} L}{A_{b} E}
$$

where $L_{r}$ is a reference length equal to $1 \mathrm{~m}, D$ is the pile diameter, $L$ is the pile length, and $E$ is the Young's modulus of the pile. In Equation (12), the first two terms $0.004 L_{r}+\frac{D}{120}$ represent the estimated displacements necessary to mobilize the side shear resistance and the end bearing resistance, respectively, and these are assumed to be valid for the relatively rigid piles in stiff, compacted silt. The third term $\frac{Q_{u l t} L}{A_{b} E}$ is the displacement corresponding to elastic compression of a free-standing rod. Together these three settlements represent the total settlement required to mobilize the ultimate axial capacity of a pile.

When interpreting the load-settlement curves for energy piles in unsaturated silt reported by Goode and McCartney [1] and replotted in Figure 2, it was found that the applied load was not sufficient to reach Davisson's criteria. Accordingly, the method of Chin and Vail [19] was used to fit a hyperbolic relationship to the measured load settlement curves, given as follows:

$$
Q=\frac{s}{m s+c}
$$

where $m$ and $c$ are constant parameters that represent the capacity at zero and infinite settlement. The capacity at an infinite settlement is $Q=1 / \mathrm{m}$. The parameters can be found by fitting a linear relationship to a plot of $s / Q$ versus settlement.

A comparison between the fitted hyperbolic curves from the Chin and Vail [19] model and the experimental load-settlement curves from Goode and McCartney (2015) is shown in Figure 2. A good fit is obtained for 
the load-displacement curves. An evaluation of the intersections between the fitted hyperbolic curves from the Chin and Vail [19] model and Davisson's line is also shown in Figure 2, indicating that the axial capacity of the energy piles increases with the pile temperature. The ultimate capacities estimated using Davisson's criterion are summarized in Table 2.

\section{Axial Force [kN]}

$\begin{array}{lllllll}0 & 500 & 1000 & 1500 & 2000 & 2500 & 3000\end{array}$

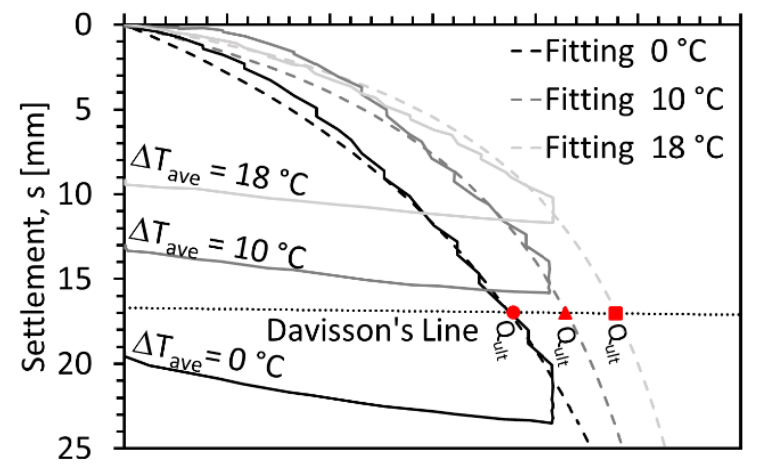

Figure 2. Assessment of the ultimate axial capacities from the fitted load-displacement curves for semi-floating energy piles under different temperatures.

Table 2. Ultimate axial capacities estimated from the three load settlement curves from Goode and McCartney [1].

\begin{tabular}{|c|c|}
\hline Test & $\boldsymbol{Q}_{\text {ult } \boldsymbol{m}[\mathbf{k N}]}$ \\
\hline$\Delta \mathrm{T}=0^{\circ} \mathrm{C}$ & 1890 \\
\hline$\Delta \mathrm{T}=10^{\circ} \mathrm{C}$ & 2145 \\
\hline$\Delta \mathrm{T}=18^{\circ} \mathrm{C}$ & 2390 \\
\hline
\end{tabular}

\subsection{Dielectric sensor correction}

The dielectric sensors at the locations shown in Figure 1 were used to monitor the volumetric water content and temperature of the unsaturated silt surrounding the energy piles. The volumetric water content data from the sensors was converted back to dielectric permittivity $\varepsilon$ using the calibration equation of Topp et al. [20]:

$$
\varepsilon=A+B \theta_{\text {raw }}+C \theta_{\text {raw }}^{2}-D \theta_{\text {raw }}^{3}
$$

where $A, B, C$, and $D$ are parameters given in Topp (1980). Then, the actual dielectric permittivity $\varepsilon_{a}$ was obtained from the measured dielectric permittivity $\varepsilon$ by removing the effect of the change in temperature $\Delta T$ using the model of Iezzoni and McCartney [2]:

$$
\varepsilon_{a}=\varepsilon-\Delta T\left(m_{V W C}+m_{d}\right)
$$

where $m_{V W C}$ and $m_{d}$ are temperature correction parameters that depend on the initial volumetric water content and initial dry density, respectively, following relationships given in Iezonni and McCartney [2]. For the compaction conditions for Bonny silt summarized in Table 1 , the values of $m_{V W C}$ and $m_{d}$ are equal to 0.123 and 0.074 , respectively. The corrected water content $\theta$ was calculated as follows:

$$
\theta=a \varepsilon_{a}+b
$$

where $a$ and $b$ are fitting parameters depending on the soil type. For Bonny silt, Iezzoni and McCartney [2] found that $a$ and $b$ are equal to 0.026 and 0.094 , respectively.

\subsection{Dielectric sensor results}

The water content data at prototype radial distances of $0.6 \mathrm{~m}, 2.4 \mathrm{~m}$, and $4.3 \mathrm{~m}$ at a prototype depth of $5.5 \mathrm{~m}$ from the surface were corrected using Equations (15) and (16). Time series of these sensors are shown in Figures 3 and 4 for the tests involving changes in pile temperature of 10 and $18{ }^{\circ} \mathrm{C}$. For the test at room temperature $\left(\Delta \mathrm{T}=0{ }^{\circ} \mathrm{C}\right)$, the changes in the volumetric water content are negligible as the temperature was constant. The results show that as the soil temperature increases a decrease in volumetric water content is observed due to thermally induced drying, with more decreases in volumetric water content for higher temperatures closer to the energy pile.

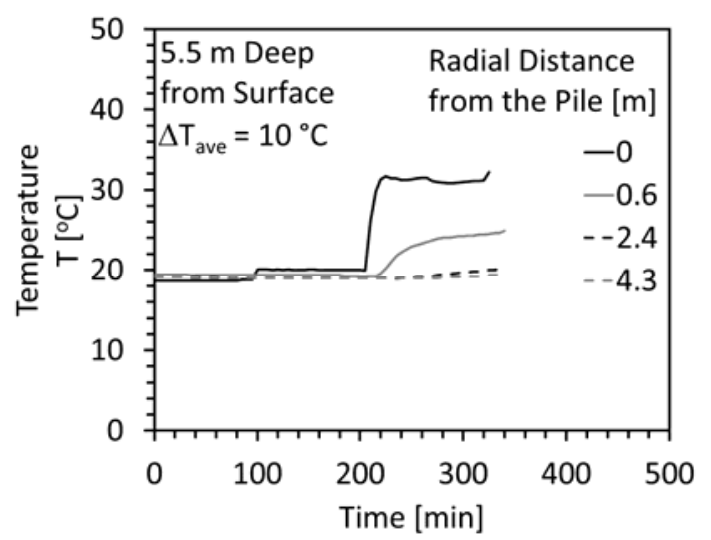

(a)

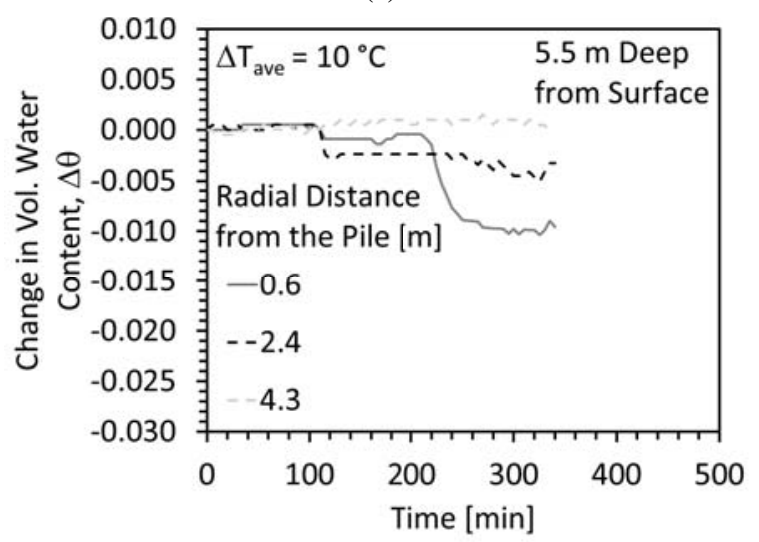

(b)

Figure 3. Dielectric sensor results at a depth of $5.5 \mathrm{~m}$ and different radial locations for the energy pile heated to $\Delta \mathrm{T}=10^{\circ} \mathrm{C}$ : (a) Temperature, (b) Change in corrected volumetric water content.

The coupled heat transfer and water flow model used by Bașer et. al. [16] and calibrated for Bonny silt was implemented into COMSOL and then used to simulate 
the soil behavior during heating of the energy piles. The profiles of temperature and volumetric water content after equilibration (i.e., before axial loading of the energy pile) from the model and experiments are shown in Figure 5. Good fits between the simulations of coupled heat transfer and water flow and the experimental data were obtained.

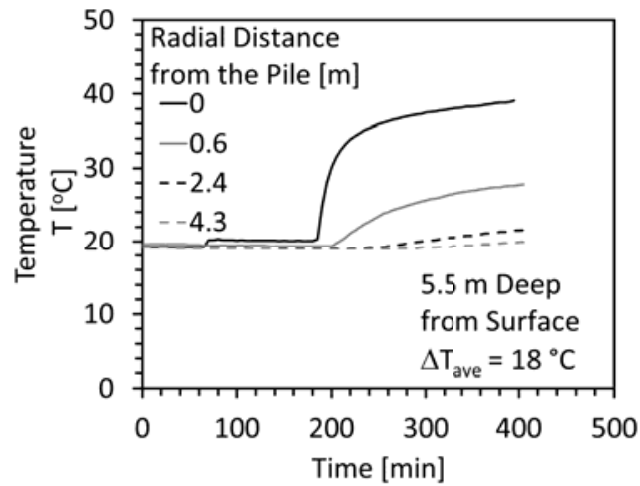

(a)

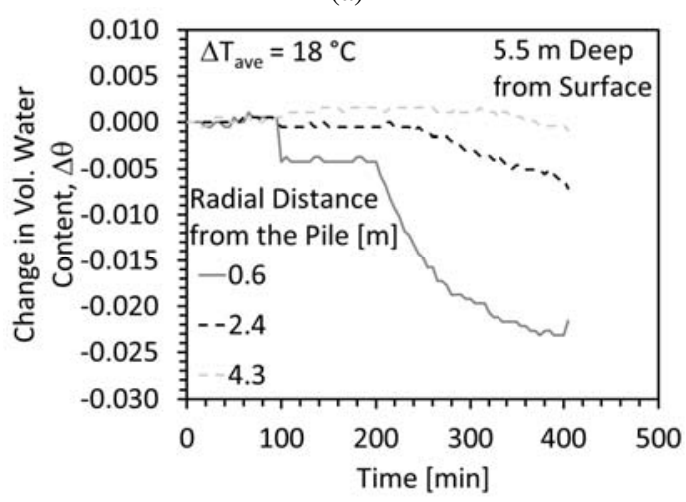

(b)

Figure 4. Dielectric sensor results at a depth of $5.5 \mathrm{~m}$ and different radial locations for the energy pile heated to $\Delta \mathrm{T}=18^{\circ} \mathrm{C}$ : (a) Temperature, (b) Change in corrected volumetric water content.

The changes in volumetric water content from the model were first used to estimate the changes in matric suction using Equation (3), and then were used to estimate the effective stress at mid-height of the pile using Equation (1), as shown in Figure 6. The results in this figure indicate that relatively large increases in effective stress can be expected at the location of the pile for the relatively small thermally-induced decreases in volumetric water content observed in Figure 5. The greatest changes in effective stress are observed close to the soil-pile interface, which has the greatest effect on the predicted pile capacity.

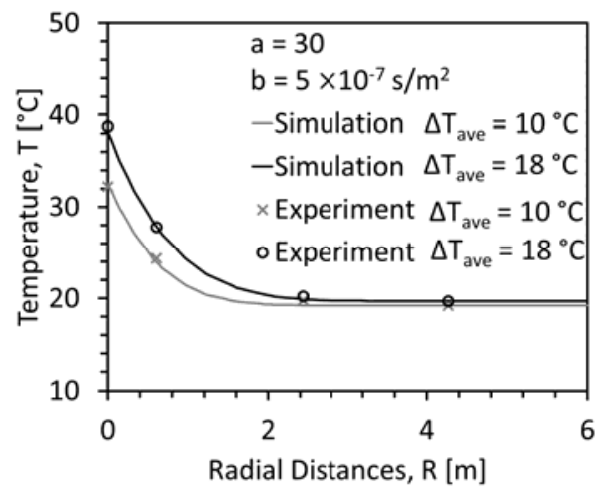

(a)

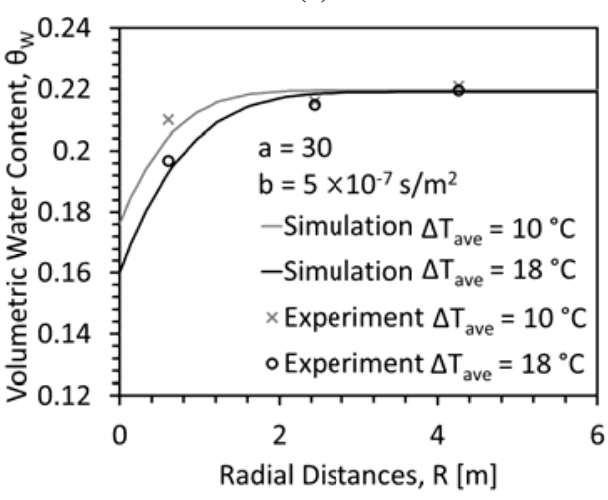

(b)

Figure 5. Comparison of radial distance from the pile for the experiments and the simulation results on unsaturated Bonny silt: (a) temperature profile, (b) volumetric water content profile.

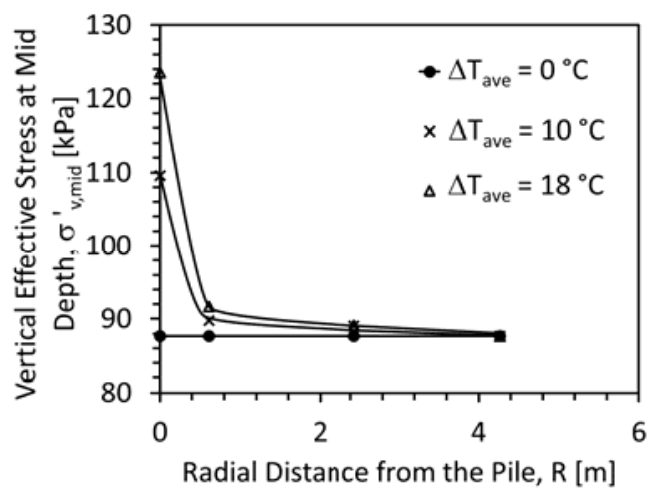

Figure 6. Effective stress at mid-height of the pile estimated using the dielectric sensor data at the time of pile loading.

\subsection{Comparison of predicted and experimental ultimate axial capacities of energy piles in unsaturated soil under different temperatures}

The ultimate axial capacity from the experiments summarized in Table 2 were first compared with the ultimate capacities for the room temperature test with $\Delta \mathrm{T}=0{ }^{\circ} \mathrm{C}$ to calibrate the values of $\beta$ and $\alpha$ used in the different equations to predict the side shear resistance at elevated temperatures. A good fit was found for a value of $\beta=0.66$. This calibrated value of $\beta$ was then used to predict the ultimate pile capacities for the tests at $\Delta \mathrm{T}=10^{\circ} \mathrm{C}$ and $\Delta \mathrm{T}=18^{\circ} \mathrm{C}$ using the values of effective stress at the soil-pile interface from Figure 6 (assuming 
that $\beta$ is not affected by the temperature). This procedure was repeated for the $\alpha$ method where a good fit to the room temperature data was obtained for a value of $\alpha=0.89$. A comparison between the predicted and experimental ultimate pile capacities with the change in pile temperature is shown in Figure 7. A good fit is obtained between the two methods and the experimental data at the two elevated pile temperatures, although both prediction methods tend to overpredict the pile capacity. The results in this figure indicate that further study should be performed to combine analyses of coupled heat transfer and water flow together with mechanical analyses of pile capacity to understand the response of energy piles in unsaturated soil layers. Further, it was not possible based on the available results to investigate the relative effects of the temperature and volumetric water content changes on the end bearing and side shear resistance using the available data, which is a topic for further study.

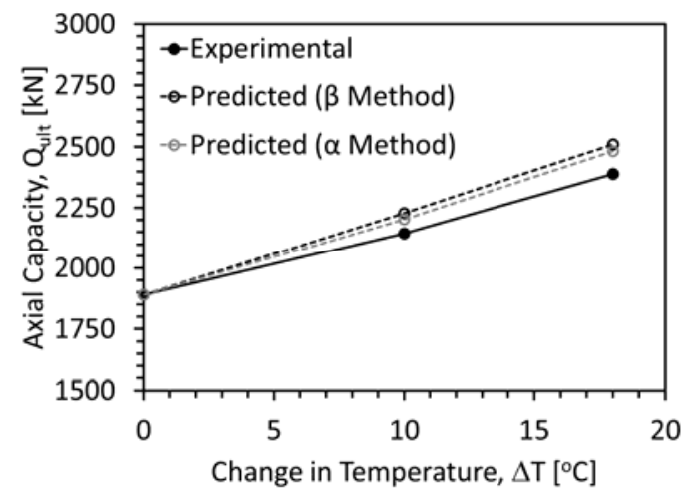

Figure 7. Pile capacity as a function of temperature from the experiments and different prediction methods.

\section{Conclusion}

In this paper, the axial capacities of semi-floating energy piles in unsaturated Bonny silt under different temperatures were investigated using geotechnical centrifuge tests and coupled heat transfer and water flow modeling. The dielectric sensors used in the centrifuge tests were interpreted using new temperature corrections, which permitted the use of an effective stress analysis to understand the increase in ultimate pile capacity with temperature observed in these tests. The dielectric sensor results indicate that the soil layer experienced thermally induced drying, leading to an increase in effective stress and a corresponding increase in pile capacity. The pile ultimate capacities for elevated pile temperatures predicted using effective stress-based equations showed a good match with the experimental ultimate capacities. Although further study is required to combine coupled heat transfer and water flow analyses with the mechanical response of energy piles, this study confirms that unsaturated soils can have a major effect on energy piles.

\section{References}

1. J.C Goode III, and J.S McCartney, Geotechnical and Geoenvironmental Engineering, 141, 8 (2015).

2. H.M Iezzoni, and J.S McCartney, Geotechnical Testing Journal, 39, 2, 169-180. (2015).

3. A.W. Bishop., G.E. Blight, Géotechnique 13, 3, 177-179. (1963).

4. S.A Grant, and A. Salehzadeh, Water Resources Research, 32, 2, 261-270. (1996).

5. N.A. Alsherif, J. S. McCartney, Géotechnique 65, 9 (2015).

6. L. Bjerrum, I.J. Johannessen, Proc. 7th ICSMFE, Mexico City, 261-264. (1965).

7. L. Bjerrum, I.J. Johannessen, O. Eide, Proc. 7th Int. Conf. on Soil Mechanics and Foundation Engineering, 27-34 (1969).

8. J.B. Burland, Ground Engineering, 6, 3 30-42. (1973).

9. C.G. Olgun, T.Y. Ozudogru, and C.F. Arson, Géotechnique Letters, 4, 3, 170-178. (2014).

10. T. Mimouni, and L. Laloui, Acta Geotechnica, 9, 3, 355-366. (2014).

11. D. Chen, J.S. McCartney, Journal of Geotechnical and Geoenvironmental Engineering, 17, 7, 04016159 (2016).

12. M. Faizal, A. Bouazza, C. Haberfield, and J.S McCartney, Journal of Geotechnical and Geoenvironmental Engineering, 144, 10 (2018).

13. J.R Philip, and D.A De Vries, Eos, Transactions American Geophysical Union, 38, 2, 222-232 (1957).

14. K.M. Smits, A. Cihan, T. Sakaki, T.H. Illangasekare, Water Resources Res., 47, 5 (2011).

15. T. Başer, J.S. McCartney, Y. Dong, N. Lu, Proc. $2^{\text {nd }}$ PanAm Conf. on Unsaturated Soils, pp. 370-380. (2017).

16. T. Başer, Y. Dong, A.M. Moradi, N. Lu, K. Smits, S. Ge, D. Tartakovsky, J.S. McCartney, Journal of Geotechnical and Geoenvironmental Engineering, 144, 7, 04018038 (2018).

17. G.A. Akrouch, M. Sánchez, J.L. Briaud, Effect of the unsaturated soil condition on the thermal efficiency of energy piles, IFCEE 2015, pp. 16181627 (2015).

18. M.T Davisson, Soil Mech. Div., Illinois Section, ASCE, Chicago, IL., pp. 81-112. (1973)

19. F.K. Chin, A.J. Vail, Proc. $8^{\text {th }}$ Int. Conf. on Soil Mechanics and Foundation Engineering, 47-52. (1973).

20. G. Topp, J. Davis, A. Annan, Water Resources Res., 16, 3, 574-582 (1980). 